\title{
Impactos materiais e imateriais na experiência de adoecimento renal crônico
}

\section{| ${ }^{1}$ Patrícia de Lima Lemos, ${ }^{2}$ Reni Barsaglini, ${ }^{3}$ Késia Marisla Rodrigues da Paz |}

Resumo: Estudo socioantropológico de abordagem qualitativa que analisou os impactos materiais e imateriais na experiência de adoecimento de pessoas adultas com insuficiência renal crônica (IRC) e tratamento dialítico. Analisados pela modalidade temática, os dados foram obtidos mediante entrevistas norteadas por roteiro semiestruturado. Organizado em dois tópicos, os resultados mostram os impactos decorrentes do processo de tornar-se adoecido renal, que abrangem as repercussões da descoberta, do diagnóstico formal e da indicação da diálise, bem como os impactos de ser adoecido renal a partir do tratamento contínuo e suas repercussões (da diálise, da relação corpomáquina), da progressão da enfermidade e seus desdobramentos. Os impactos envolvem a dimensão material e imaterial, compreendendo fraqueza e dores constantes, relação de raiva e gratidão com a máquina de diálise, marcas ocasionadas pela fístula arteriovenosa, comorbidades, depressão, iatrogenias, isolamento social, dentre outros. Conclui-se que os diferentes impactos gerados pela IRC não se dissociam na sua existência corporal e são amplificados ou amenizados por aspectos biográficos, sociais, culturais e econômicos e que, apesar do mesmo diagnóstico, as pessoas vivenciam a IRC e seus impactos de modo singular.

> Palavras-chave: insuficiência renal crônica, impactos, experiência de adoecimento.

\author{
1 Universidade Federal de Mato \\ Grosso. Rondonópolis-MT, Brasil \\ (patricialimaenf@gmail.com). \\ ${ }^{2}$ Instituto de Saúde Coletiva, \\ Universidade Federal de Mato \\ Grosso. Cuiabá-MT, Brasil \\ (barsaglinireni@gmail.com). \\ ${ }^{3}$ Universidade Estadual de Mato \\ Grosso, Cáceres-MT, Brasil \\ (kmrpaz@gmail.com).
}




\section{Introdução}

A insuficiência renal crônica (IRC), clinicamente definida como a perda progressiva e irreversível da capacidade renal (ZATZ, 2014), tem sido importante problema de saúde pública no Brasil. O país apresenta a terceira maior população de diálise no mundo, com nível de ascensão alarmante (LUGON; MATTOS; WARRAK, 2014).

Este artigo privilegia o ponto de vista dos adoecidos por IRC, em situações concretas do mundo da vida, envolvendo questôes objetivas, subjetivas, intersubjetivas, limitações, significados e formas de enfrentamento (CANESQUI, 2007), ou seja, a experiência de enfermidade que, compreende a "forma pela qual os indivíduos se situam perante ou assumem a situação de doença, conferindo-lhe significados e desenvolvendo modos rotineiros de lidar com a situação" (ALVES; RABELO, 1999, p. 171).

Por seu caráter permanente e por demandar cuidados constantes, a IRC se configura como adoecimento crônico, entendido como um estado que demanda gerenciamento contínuo, gera incertezas e afeta adoecidos, familiares e o sistema de saúde, com impactos de ordem médica e social (CANESQUI, 2007; BARSAGLINI, 2015).

Discussões de autores pioneiros pontuam sobre o processo de gestão dos adoecimentos crônicos que envolvem diferentes tipos de trabalho em torno das consequências e dos problemas cotidianos (CORBIN; STRAUS, 1985). Ademais, o desafio para o adoecido crônico não se restringe ao controle dos sintomas e da doença em si, mas, sobretudo, viver o mais normalmente possível, o que remete à posição ativa daquele que sofre diante dos desdobramentos diários (STRAUSS, 1985).

Os impactos se referem a tais desdobramentos ou às repercussões de algo novo (no caso, o adoecimento renal) introduzido numa dada realidade. No entanto, apesar do adoecimento crônico afetar todos os aspectos da vida, o impacto sentido difere individualmente, devido às características de personalidade e dos sistemas de apoio recorridos e aos demais fatores que o influenciam de forma personalizada (LUBKIN; LARSEN, 2002). 
Nesse tipo de adoecimento, os impactos podem ser materiais - incidindo nas características das pessoas como no corpo, aparência, nas condições de vida e de trabalho - e imateriais/simbólicos - como nas imagens corporais, valores, conhecimentos, símbolos, significados e sentidos. Tais dimensões, no entanto, não são dissociadas nem estáticas, mas se confundem e influenciam circularmente (RAYNAUT, 2006).

Devido à longa duração dos adoecimentos crônicos, seus impactos diluem-se na experiência, compondo-a. Então, para compreendê-los, é fundamental considerar a situação biográfica das pessoas que resulta do ambiente social e cultural, do status e papel exercido dentro de determinado contexto, como também a posição moral e ideológica do adoecido (SCHUTZ, 1979). Fazem parte da dimensão biográfica as histórias, a sedimentação de experiências anteriores ou estoque de conhecimento e os propósitos futuros próprios do sujeito (SCHUTZ, 1979).

As rupturas de rotinas que afetam o fluxo da vida, a organização e a ordem cotidianas são expressões dos impactos dos adoecimentos crônicos. Entre elas, há as que se aproximam do conceito de epifania proposto por Denzin (1989) para se referir às experiências problemáticas e marcantes na vida das pessoas, como crises que modificam as estruturas de sentido fundamentais em suas vidas, com efeitos positivos ou negativos.

Assim, como parte de uma pesquisa mais ampla (LEMOS, 2014), este artigo analisa os impactos materiais e imateriais de homens e mulheres que convivem com a IRC, os quais, para fins de apresentação, foram organizados em dois tópicos: os impactos do tornar-se renal, que processualmente incluem as transformações provocadas pela descoberta, pelo diagnóstico e pela indicação do tratamento; e os impactos do ser renal, a partir do tratamento contínuo e suas repercussões (da diálise, da relação corpo-máquina), bem como da progressão da enfermidade e seus desdobramentos.

\section{Procedimentos metodológicos}

Trata-se de um estudo de abordagem qualitativa, realizado com adultos selecionados em um Centro de Nefrologia - serviço atualmente sob administração pública municipal - que atende toda a região de abrangência do Polo de Saúde da região Sul do estado de Mato Grosso, composta por dezessete municípios. 
Os sujeitos foram identificados mediante consulta a arquivos do serviço, que possibilitou o acesso à lista das 117 pessoas cadastradas, sendo selecionados aqueles da faixa etária entre 20-59 anos e em tratamento de diálise peritoneal ou hemodiálise, justificando-se pelo pressuposto de variação dos impactos em decorrência do período de ocorrência na vida como também pela modalidade de tratamento.

Aplicando-se os critérios de inclusão, obtivemos 46 potenciais informantes. Então, iniciamos as entrevistas convidando homens e mulheres a partir dos que tinham mais tempo de diagnóstico, pressupondo a aprendizagem de manejo dos impactos da IRC. A delimitação do número de sujeitos deu-se pela técnica da saturação dos temas (FONTANELLA; RICAS; TURATO, 2008), totalizando dez participantes.

Para a produção dos dados, valemo-nos de entrevistas guiadas por roteiro semiestruturado, gravadas e realizadas na residência dos participantes. Diante da dificuldade em comunicar determinados impactos, complementamos os dados pela técnica de desenho, em que se apresentavam as figuras de dois corpos, solicitava-se que os participantes as completassem mostrando como era um corpo com e sem a IRC. Após a elaboração do desenho, pedíamos para explicar as representaçôes empreendidas (VÍCTORA, 2000). No entanto, devido à profundidade e importância do conteúdo dos desenhos, estes foram reservados para posterior publicação, que encontra-se em elaboração. Para o tratamento dos dados, foi utilizada a análise de conteúdo temática não tradicional, identificandose núcleos de sentido nas falas (MINAYO, 2011).

A média de idade dos participantes era de 48,3 anos, sendo quatro mulheres e seis homens, a maioria com ensino fundamental incompleto. Sete eram casados, uma viúva e dois solteiros. Entre os dez participantes, nove faziam tratamento de hemodiálise e um fazia diálise peritoneal, sendo que o tempo de tratamento oscilou entre 5 e 23 anos. Quanto à renda, sete recebem o Benefício de Prestação Continuada (BPC) (subsídio do Instituto Nacional do Seguro Social), correspondendo a um salário mínimo ( $\mathrm{R} \$ 724,00$ na ocasião) e os demais referiram renda de 3 a 5 salários mínimos.

A pesquisa foi aprovada pelo Comitê de Ética em Pesquisa do Hospital Universitário Júlio Müller, parecer no 528.479 de 12/02/2014, atendendo à Resolução no 466/2012 do Conselho Nacional de Saúde. Observando os 
preceitos da resolução, os nomes aqui empregados são fictícios, escolhidos pelos participantes por ocasião das entrevistas.

\section{Impactos do tornar-se adoecido renal: a descoberta, o diagnóstico e a indicação do tratamento}

A experiência de adoecimento começa muito antes do diagnóstico formal feita pelo saber biomédico, pois seu início compreende sensações e alterações, sinalizando que algo não vai bem (ALVES, 2006). Não é diferente o caso da IRC, quando tais sensações são seguidas de complicações específicas do acometimento renal que culminaram com o diagnóstico, indicando grau avançado de deterioração dos rins.

Tais acontecimentos compõem o processo de tornar-se doente, havendo transição de um estado para outro (MELEIS; TRANGENSTEIN, 1994), que, a depender do tipo de adoecimento, é mais ou menos longo e abarca a percepção de alterações corporais. Justamente por isso, nem sempre finaliza-se a transição com o diagnóstico formal, como nos casos em que, mesmo com o reconhecimento biomédico, a pessoa não se sente propriamente doente.

Os relatos dos adoecidos renais também remetem à obra de Arthur Frank, em que se pontuam três tipos de narrativas básicas realizadas pelo corpo ferido: da restauração, do caos e da indagação. Os elementos narrativos propostos pelo autor possibilitam identificar nos relatos aspectos que transcendem os impactos, pois explicitam o movimento de mudança e aprendizado em decorrência do adoecimento, em que o corpo ferido passa a ser tema de suas histórias e condição para contá-las. Assim, o fato de contar história possibilita "dar voz" ao corpo ferido, e, desvela aspectos pessoais e sociais (FRANK, 2013).

Destarte, tornar-se doente envolve aprendizagem, conhecimento e experiência. $\mathrm{O}$ adoecido aprende a lidar com a situação e, com isso, será especialista em sua própria condição (LUZ; BASTO, 2013). Os sinais vagos sinalizam esse processo:

Meu tornozelo inchava muito [...]. E as costas doíam muito [...] dor de cabeça [...] dor no corpo no geral [...] já tinha pressão muito alta, também [...]. (Ledelaine, 44 anos, hemodiálise).

Entre os entrevistados, foi recorrente o diagnóstico tardio; deparando-se com a insuficiência renal já em estado avançado, houve, simultaneamente, a indicação do tratamento dialítico imediato, situação que corrobora os achados de MercadoMartínez et al. (2015). 
Além de impactos físicos da descoberta tardia, somam-se aqueles decorrentes das representaçôes mobilizadas sobre a condição de adoecido renal, como se nota no excerto a seguir, em que se vislumbra a proximidade da morte e, como reação, a liberação a outros prazeres. Há, ainda, as representações sobre o tratamento invasivo ao qual o sujeito é impelido a se submeter, representado pela máquina.

O tratamento dialítico contínuo passa a compor o cotidiano da pessoa, demandando contato regular com profissionais e serviços especializados de saúde, bem como o seguimento dos protocolos de assistência formulados pela esfera médica, submissão aos procedimentos de diálise, consumo de medicações, restrições alimentares, exames periódicos.

Não obstante, as especificidades do tratamento trazem modificações na rotina. Se há impactos envoltos em sofrimento, com o passar do tempo eles são ressignificados na experiência ("encarar como normal", como um deles disse), pois, enfim, o tratamento se torna uma condição para manter e salvar suas vidas. Notemos nas suas palavras:

[...] Mas agora o problema renal me pegou de jeito, né! Me pegou de jeito porque eu sofri muito eu achava que ia morrer e que eu já tinha assim como morte: o renaaallll [...] $\mathrm{Na}$ realidade, eu pirei e foi muito difícil [...] muita tristeza [...] porque eu ia deixar as pessoas que eu amo e comecei a sofrer muito, uma melancolia, uma depressão muito violenta e aí eu cai na vida eu achei que eu ia... bom eu vou morrer, eu vou beber bastante, eu vou namorar bastante, eu vou comer de tudo. Eu tô ferrado [...] (Ari, 43 anos, hemodiálise).

[...] Quando eu me deparei com aquilo eu chorava tanto [...] foi um choque, né, desespero. Primeira hora que eu tive na clínica eu me deparei com umas imagens muito feias lá dentro, assim, porque eu não conhecia nada, né. Hoje pra mim é normal [...] mas depois eu comecei a encarar como uma coisa normal, porque eu preciso da máquina pra sobreviver, graças a Deus tem a máquina [...] (Zeza, 50 anos, hemodiálise).

Trata-se, também, do primeiro contato com o serviço especializado, que agrega recursos tecnológicos característicos dos níveis de média e alta complexidade em saúde. No caso, a internação sugere gravidade, em uma condição da qual anteriormente só ouvira falar, era imaginada e que se encarna agora na sua biografia, como afirmam:

Quando ele falou que eu tinha que fazer diálise eu fiquei uns dez dias no hospital internada, aérea [...] uma pessoa assim que parece que estava desligada, o choque foi tão grande que eu estava passada (Elizabeth, 51 anos, hemodiálise).

Aí de lá mesmo ela [a médica] já me mandou com uniforme e tudo pra internar no [Hospital] e foi colocando o cateter no pescoço já, daí foi a hora que eu entrei em de- 
pressão, parece que tinha acabado o mundo pra mim, porque eu não aceitava! (Diego,

43 anos, hemodiálise).

[...] O duro é quando falou assim "você vai fazer hemodiálise", aí você pede pra morrer [...] Porque eu sempre ouvi falar desse problema nos rins e da hemodiálise, mas nunca imaginava que era um sofrimento igual aquele [...] Aí é a mesma coisa de parar no fundo do poço, meu Deus! Fiquei desesperado! (José, 54 anos, diálise peritoneal).

Enfim, o diagnóstico inesperado tem impactos que vão se somando às modificações físicas e emocionais decorrentes, não exclusivamente da enfermidade em si, e potencializando-se ainda mais a partir da indicação da terapia dialítica ininterrupta. Para fins de análise, destacamos a seguir os desdobramentos deste tratamento na relação corpo-máquina e nas respectivas consequências corporais.

\section{Impactos do ser adoecido renal: as repercussões da diálise, a relação corpo-máquina, a progressão da enfermidade e seus desdobramentos}

O tratamento substitutivo na IRC biomedicamente diagnosticada envolve cuidados contínuos, como a diálise (hemodiálise ou peritoneal), os medicamentos e a dieta, sendo que, todos eles têm repercussões de natureza e graus variados e imbricados (ZATZ, 2014).

Uma vez indicado e iniciado, o tratamento dialítico precisa ser ininterrupto, com sessões regulares, podendo se tornar importante fonte de sofrimento, situação à qual, diante da cronicidade, as pessoas são levadas a se conformarem, ainda que a estranhem.

Dentre os impactos do tratamento, os sintomas físicos são frequentes. Aparecem nos relatos as sensaçôes desagradáveis, incômodas, com destaque para a fraqueza e dores constantes, seguidas de náuseas, vontade de urinar, dificuldades na respiração e inchaço, confirmando-se o que verificaram outros estudos (RAMOS et al., 2008; MATTOS; MARUYAMA, 2009; TERRA et al., 2010; GONÇALVES, 2012).

A fraqueza, náuseas, às vezes eu fico com o corpo todo dolorido né? Tudo doído né? Cabeça parece que tá cheia de água, aquele barulhão na cabeça, e fraqueza né? (Elizabeth, 51 anos, hemodiálise).

Fraqueza, desânimo, moleza no corpo, nas pernas, e as pernas também estão dormentes né [...] (Francisco, 56 anos, hemodiálise). 
Entre tais impactos, é comum a vontade de urinar, frustrada pela não concretização. Chama atenção a reação diante dessa incoerência no caso de Diego, a partir da tentativa de passar uma sonda vesical no intuito de conseguir urinar. Percebe-se que sua atitude se baseia em concepções leigas de fisiologia e funcionamento corporal interno:

No meu caso, o meu atrofiou, ficou pequeno, secou e diminuiu bastante [...] já tentei até colocar sonda pra ver se eu urinava, quase me machuquei. Eu mesmo colocando manual (Diego, 43 anos, hemodiálise).

Outro sintoma referido que ganha destaque é a dor permanente, haja vista que comunicá-la é algo problemático por se tratar de sensação cuja interpretação passa por parâmetros subjetivos, influenciada pelo tecido cultural e social circundante, englobando crenças e a visão religiosa que lhe são favoráveis. As metáforas constituem recursos para organizar uma experiência que de outra forma seria indizível, incomunicável (LE BRETON, 2007), auxiliando na comunicação, no caso, da dor. Nesse sentido, a entonação sugere a sua intensidade, como se nota na fala abaixo:

É uma doença. E pra falar a verdade é uma doença sofrida, porque você tem um problema renal que dá cólica, é dor demais [...] DOOOOR dia e noite, dia e noite sem parar, você tomava medicamento, aliviava, aí voltava, tomava remédio direto. (José, 54 anos, diálise peritoneal).

A dor, conduzida por aspectos fisiológicos, escapa ao controle daquele que a sente e de sua consciência. Trata-se de um dado biológico, interpretado individualmente; por isso, possui significação própria (FERREIRA, 1994; LE BRETON, 2007).

Os dispositivos e procedimentos necessários ao tratamento dialítico, como o Cateter Venoso Periférico (CV), a Fístula Arteriovenosa (FAV), as punções venosas e a própria máquina, além de invasivos, são marcas que informam sobre a condição instalada em seus corpos, além de gerarem dor. Chamam a atenção as expressões "assombroso" e "doía na alma" nos relatos, sinalizando o impacto diante do desconhecido e a não dissociação corporal, que ultrapassa a dimensão física e alcança também o imaterial, fundindo-se.

No corpo é que transcorrem experiências biográficas em um tempo e espaço, podendo ganhar materialidade, significação; ou seja, o mundo é corporificado. Recorre-se aqui ao termo corporificação (como uma das traduções do termo embodiment para o português) como reação e recusa de dualismos e falsas 
dicotomias, como, por exemplo, corpo/mente, corpo/alma, entre outras empreendidas pela Antropologia da Saúde através das contribuições teóricas de Csordas $(1990 ; 1994)$. Nesse sentido é que o autor afirmará que o sofrimento não apenas se expressa, mas, fundamentalmente, se experimenta no corpo. Lembramos que o adoecimento é um tipo de sofrimento ou parte dele.

Ah, quando eu vi o cateter... que ia colocar assim no pescoço, achei que era o fim do mundo, eu achava que ia morrer [...] Quando foi feita a primeira fistula, vou falar pra você, foi muito assombroso (Elizabeth, 51 anos, hemodiálise).

No começo eu fechava os olhos porque eu não gostava de ver [...] aquelas mangueiras cheias, ai meu Deus, aquilo me irritava, incomodava, sabe? Doía minha alma sabe? (Zeza, 50 anos, hemodiálise).

A relação com a fístula, assim como com a máquina, é ambígua, causando estranhamento e assimilação, pois é algo que passa a fazer parte do corpo e que requer cuidados contínuos. Essa capacidade corporal de adaptar tecnologias em si, para a sua conservação e melhoramento, como a máquina e a fístula, remete ao corpo ciborg de Haraway (2009), resultante do ajuste entre a mecanização do ser humano, a partir de um prisma, e de outro da humanização e subjetivação da máquina. Os relatos confirmam:

[...] No começo, foi difícil porque sempre que eu entrava no quarto que a máquina ficava eu olhava batia de frente com a máquina e levava um baque assim, chorava um pouco, sofria, mas aí fui me acostumando com ela, foi passando a fazer parte da minha vida [...] Aquelas agulhas, igual eu te falei, detonam a gente. É muito grossa [...] Incomoda a agulhada, as agulhadas... dói, mas a gente acostuma com tudo. É pro bem. (Ari, 43 anos, hemodiálise).

[...] Aí, depois de uns três meses, tiraram o cateter e passou pro braço que é a fístula né, aí com trinta dias começou a furar minha fístula que eu tenho até hoje, eu cuido muito dela [...] (Ledelaine, 44 anos, hemodiálise).

Também é notória a formação de pseudoaneurismas nas áreas puncionadas nas fístulas, representando traços depreciativos, estigmas, como tratou Goffman (1988): marcas que comunicam informaçôes sobre uma identidade deteriorada. Tais marcas rompem com a transparência do corpo ordinário (LE BRETON, 1995), impondo sua presença e a condição diferente da pessoa - perturbam. Observa-se nos depoimentos:

Às vezes incomoda quando você tá em algum lugar e a pessoa fica te olhando, né. Tem gente que até pergunta, sabe, e eu dentro da minha maior boa vontade, eu respondo "é realmente eu faço hemodiálise e o braço vai ficando assim porque vai danificando de tanto furar" [...] (Zeza, 50 anos, hemodiálise). 
Tem pessoas que ficam olhando a fístula e perguntam, mas eu já acostumei, respondo normal. Só uma vez que eu dei uma resposta mal criada pra uma mulher. Eu sai ruim da máquina, aí fui para um ponto de ônibus e a mulher perguntou se eu estava usando droga porque coloca aqueles curativinho, né? Aí eu falei que era [risos]. Mulher besta, né? (Maria, 50 anos, hemodiálise).

Vigora a compreensão da artificialidade da ação substitutiva na diálise, que impôe condições fragilizantes ao retirar mais do que o necessário do corpo. Nesse sentido, concorda-se que "cada vez mais a técnica é capaz de substituir o orgânico, de aumentar as performances do corpo...” (LE BRETON, 2011, p. 396), porém, no caso, essa substituição é parcial. Como desdobramentos, haverá impactos secundários decorrentes do uso contínuo de suplementos e medicamentos orais e injetáveis (somados àqueles prescritos para as comorbidades) como vitaminas, ferro, antifosfatos, anti-hipertensivos, hipoglicemiantes, eritropoietina, dentre outros, como também verificaram Zillmer, Silva e Mercado-Martinez (2015), a partir da investigação com pessoas em diálise peritoneal, que pontuaram efeitos colaterais diversos decorrentes dos medicamentos. Destaca-se a menção ao impacto das vitaminas, lembrando sua valorização em determinados contextos culturais como fortificantes (DUARTE, 1986) e a remissão à fraqueza diante de sua carência:

Enfraquece os ossos, porque a vitamina do corpo a máquina tira [...] Acho que é devido um pouco também ao tratamento da hemodiálise, dai fica fraco o organismo da gente, os "nervos". Que nem a doutora, os doutores já falaram que a gente tem que evitar de bater, de cair, de machucar, porque o organismo da gente é muito fraco, o osso tá muito fraco (Diego, 43 anos).

[...] Ela filtra, né, passa o sangue no filtro e devolve... Puxa né o sangue passa na máquina e devolve filtrado... Aí vão as vitaminas, no filtro não devolve todo o sangue né, fica um pouco de sangue nas mangueiras, no filtro, aí tem que tomar os remédios pra repor [...]. (Francisco, 56 anos).

Aquela máquina tão inteligente, mas ela não tá fazendo o suficiente! Vamos assim dizer por que ela tira tudo da gente o bom e o ruim. O ruim e o bom, você tá entendendo? (Ari, 43 anos).

Incluem-se também os impactos decorrentes das restrições alimentares exigidas diante da condição de deterioração renal, que acarretam alterações metabólicas. A terapia nutricional é considerada um dos aspectos mais importantes para quem tem problema renal (MARTINS; RIELLA, 2014), de modo que as recomendaçóes pertinentes fazem parte do tratamento com o intuito de manter ou restabelecer o estado nutricional e a qualidade de vida. As 
restrições alimentares representam uma importante fonte de sofrimento, não só pela dimensão biológica, mas também pela simbólica, dado que a comida e o ato de comer são carregados de significados, que compreendem rituais, costumes, normas, escolhas, ocasiōes significativas, sociabilidade, dentre outros aspectos, envoltos pela cultura e sociedade que as pessoas vivem (CANESQUI, 2005).

Todavia, é notório que, na convivência com o tratamento, as pessoas vão contornando as limitaçôes, aprendendo com as sensações corporais na prática cotidiana, os tipos e a quantidade ideal dos alimentos, mobilizando recursos e desenvolvendo estratégias para amenizar os efeitos desagradáveis (CANESQUI, 2005):

No começo eu chorava, dava muita revolta, parece que aí que aumenta a ansiedade de você comer e beber [...]. Comida tem que ter pouco sal, eu tenho que comer ela fria porque normalmente o sal além dele subir a pressão ele puxa a água né? [...]. Pouca gordura, sempre mais magra, tudo mais controlado né? (Elizabeth, 51 anos).

[...] Você não pode comer as coisas que você gosta [...] isso aí pra mim já foi o sofrimento [...]. Carne é só um pouquinho, comida tem que se pouco, massa não pode [...] aquele tal de potássio e fósforo que sobe pra quem tem problema dos rins [...]. (José, 54 anos).

Eu consigo controlar, se é pra eu comer uma banana eu não como ela inteira, e ai é assim que eu vou controlando [...]. (Ledelaine, 44 anos).

[...] Porque a anemia pega a gente [...] muita fraqueza [...] acho que um pouco é alimentação [...] (José, 54 anos).

Como ambivalência da Medicina contemporânea, se seus avanços permitem a melhora da qualidade de vida das pessoas em relação a uma série de agravos, como contrapartida, há os efeitos secundários não desejados engendrados pelos próprios cuidados de saúde/intervenções (AYRES, 2005), classicamente discutidos como iatrogênese clínica por Illich (1975). Nos casos analisados, notase que as hospitalizações necessárias e os procedimentos, como inserção de cateter e punções venosas, são condições clínicas que engendram novas enfermidades.

Tirou o cateter porque dava muita bacteremia né [...] Eu tinha bacteremia direto assim na máquina. No primeiro mês não, mas do segundo em diante era entrar na máquina e me dava aquela bacteremia e depois dói, dói tudo o corpo, né [...] (Zeza, 50 anos, hemodiálise).

Também constituem ambivalências do tratamento as sensações desagradáveis recorrentes após as sessões de hemodiálise, que geram situações impactantes, necessitando que se aprenda a lidar com as complicações diárias ao longo do 
tempo. Isso porque, embora a Medicina tenha avançado no que concerne à tecnologia e obtido avanço no prolongamento da vida de modo geral, pouco tem sido o empenho de minimizar os problemas que transcorrem nas vidas cotidianas dos adoecidos renais, como pode-se notar no caso dos entrevistados:

[...] A água que eu bebo, o rim não filtra mais, não passa pelo rim mais, não vai mais, daí fica no corpo [...]. Você tá cheio de líquido e o coração tá cheio de líquido também, fica inchado, na hora que você tira o peso ${ }^{1}$ [na diálise] você fica acabado. (Diego, 43 anos, hemodiálise).

Dá falta de ar. [...] De vez em quando dá câimbra, quando retira muito peso né... (Miúdo, 54 anos, hemodiálise).

Tem dias que eu fico baqueada mesmo, sabe? Aí eu tenho que chegar, deitar, recuperar, descansar né? Ai só no outro dia que eu vou tá com minhas energias novamente, minhas forças, né [...] (Zeza, 50 anos, hemodiálise).

Como é típico dos adoecimentos crônicos, eles mudam ao longo do tempo, já que também as pessoas, seus contextos e corpos são diferentes e se desgastam desigualmente, desestabilizando a normalidade e rotina sempre provisoriamente estabelecidas (BARSAGLINI, 2015). Assim éque outras complicações secundárias da IRC levaram a outras condições crônicas e mais intervenções (cirúrgicas, no caso a amputação e o transplante renal sem sucesso). Lembremos, ainda, do quadro de comorbidades que reciprocamente acentua os impactos da IRC, tanto por aquelas enfermidades de base quanto por outras que surgem no decorrer do tempo, como hipertensão, diabetes, osteoporose, dentre outras; causalidade reforçada por profissionais de saúde. Os entrevistados relatam:

[...] Agora depois da perna [amputação] eu não consigo mais fazer nada, né [...] (José, 54 anos, diálise peritoneal).

O transplante foi em Cuiabá e foi, assim, transplante de cadáver. [...] Esse rim que transplantou em mim ele só durou cinco dias, ele deu uma rejeição. Aí depois fiquei na UTI uma porção de dia e fazendo diálise do mesmo jeito (Elizabeth, 51 anos, hemodiálise).

É que eles falaram assim que conforme o tratamento da gente vai prolongando, vai aparecendo coisa, né [...] vai mexendo com seu organismo e vai aparecendo coisa. Aí eu creio que é por causa disso porque era boa minhas vistas agora tá prejudicando [...] (Ledelaine, 44 anos, hemodiálise).

[...] Agora deu cisto, né? Deu cisto no rim, não tinha e agora que eu fui fazer exame deu. Disse que tem um cisto pequeninho... (Maria, 50 anos, hemodiálise).

Outras sensações e sintomas chamam atenção nos relatos, como a "agonia", "depressão" e "dor no peito", que podem indicar processos de sofrimento 
mental devido à situação em que se encontram. Contudo, deve-se notar que essa dimensão mental não se dissocia da física, material e moral, como a dor no peito vinculada à agonia ou a depressão por ter parado de trabalhar. Novamente, parece estar presente a ideia de que o corpo, sua fisicalidade e o processo de saúdeenfermidade estão integrados à dimensão moral da vida social (SEPARAVICH; CANESQUI, 2010). É que a experiência nesse processo envolve não somente a corporalidade imediata, mas uma gama de sentimentos, sentidos e valores que são mobilizados pela sociedade e pelos agentes sociais, como já apontava Duarte (2003). Como referiram os entrevistados:

Sinto assim uma dor no peito, dá aquela agonia no peito dá vontade de chorar (Diego, 43 anos, hemodiálise).

A gente chora, né. Lembra do que você fazia e agora depende dos outros não é fácil não, mas a gente conforma com a vida, né? (José, 54 anos diálise peritoneal).

Eu sempre trabalhei [...] aí parei de trabalhar de uma vez [...] acho que por isso que me deu depressão [...] (Maria, 50 anos, hemodiálise).

Embora investigar a sexualidade não tenha sido um dos objetivos deste estudo, um dos entrevistados referiu vagamente sobre o comprometimento sexual, expressando-se como repercussão da IRC. Informou-nos de modo específico que, com o passar do tempo, houve acentuada diminuição da sua afetividade, podendo estar associada ao aspecto psicológico e emocional, não restrito à fisicalidade, como discutido acima.

A afirmação do entrevistado contrasta com o que a sociedade ocidental espera do homem, devendo este estar sempre pronto e disposto sexualmente, trazendo à tona atributos da sexualidade masculina e masculinidade hegemônica (GOMES, 2008). Outras investigaçôes encontraram a sexualidade masculina associada à dimensão moral, como a de Separavich (2014), em casos de hipertensão e, também, Rodrigues et al. (2011), que observaram alterações na sexualidade após o início da hemodiálise:

A pressão alterou, né? Sexualmente falando, diminuiu, então a cadeira de rodas nunca foi problema pra minha sexualidade, mas quando eu comecei a fazer a diálise eu não sei se tanto... não sei se muito foi o psicológico também, né? Fui ficando cada vez mais frio, frio, frio e isso mudou muito também [...] (Ari, 43 anos, hemodiálise).

No imbricamento de aspectos materiais e imateriais, observam-se também impactos na sociabilidade imputados pela cronicidade com o tratamento permanente da hemodiálise, pois a dependência do serviço especializado impõe 

certo isolamento social, como sugerem os excertos:

Você fica parado [...] eu não sou de ficar parado, eu vou pra beira do rio, pra casa dos vizinhos... Aí eu não fico quieto dentro de casa, se eu ficar, eu fico estressado [...] (Miúdo, 54 anos, hemodiálise).

Só Deus sabe o sofrimento da gente nesse tratamento, não tem liberdade de viajar, você fica preso, pior que uma cadeia. Você não tem liberdade de viajar, você não tem liberdade de sair com a família pra lugar nenhum e quando você vai ali em Cuiabá tem que arrumar vaga ${ }^{2}$ [para fazer diálise] [...] É difícil, aí eu já tentei até fazer besteira comigo mesmo na época: me matar! (Diego, 43 anos, hemodiálise).

Em um plano mais amplo, a convivência com a IRC e o tratamento permanente impõe restriçôes que repercutem nos valores de liberdade e independência, muito comuns ao universo masculino, mas sem esquecer o contexto capitalista, que imprime peculiaridades àqueles impactos e seus significados. O impacto do tratamento ganha dimensão importante quando associado à impossibilidade de manter as atividades laborais cotidianas, principalmente devido à manutenção da renda, que exacerba o sofrimento das pessoas, mais acentuadamente nos homens, pois compromete o papel de provedor efetivo e trabalhador da casa. Segundo Nardi (1998), o valor simbólico do trabalho faz parte das atribuiçôes constitutivas da identidade masculina; por isso, a impossibilidade de exercê-lo poderá resultar em conflito de identidade. Isso é percebido nas colocações dos entrevistados:

Muda tudo; a minha liberdade acabou né? Não tenho liberdade pra nada, você não pode fazer nada [...] Eu olho pra essa moto eu montava e ia... Agora eu vejo ela aí, e eu dependente dos outros [...] (José, 54 anos, diálise peritoneal).

[...] Quando eu trabalhava eu tinha dinheiro, né? E agora? É só esse salarinho que dá má-le-má só pra pagar as contas e comer na marra... Quando trabalhava tinha dinheiro, roçava pasto, fazia cerca, fazia estrutura, tocava peão no serviço, pegava pasto, eu tinha dinheiro... Agora chegou naquele mês, trinta dias, só aquele miado... vai lá paga conta e mais trinta dias [...] (Miúdo, 54 anos, hemodiálise).

[...] Tive que parar de trabalhar, né... Três vezes por semana, né, quatro horas, não tem como não... As vezes a gente sai muito ruim de lá, fica muito ruim [da hemodiálise] (Francisco, 56 anos, hemodiálise).

Notou-se que tais restrições entre os participantes foram mais acentuadas entre os homens, mas também foram observadas entre as mulheres no estudo de Mercado-Martinez et al. (2015), o que faz concluir, portanto, haver impactos 
naqueles valores e na sociabilidade de modo geral, mas em graus variados porque interseccionados por outros elementos além do gênero.

Quanto aos diferenciais dos impactos em função das modalidades de hemodiálise e diálise peritoneal, vislumbrou-se que, no entrevistado que se encontrava nessa última situação, os impactos eram mais amenos se comparados:

Aí o doutor " $M$ " conversou comigo né... Aí eu conheci uma pessoa também, a "F" [...]. Ela explicou que era pra ficar em casa [...]. Mostrou lá como que era [...]. Aí pensei "se for por sofrimento eu vou nesse ai" [...] Pelo menos estou em casa, né? [...] Aí colocou o cateter [o abdominal]; o pessoal me ensinou uns dois dias, aí eu aprendi e agora faço tudo! Depois que eu fiz, eu melhorei, que eu fico em casa né, não fico lá naquele trem [na hemodiálise] vendo gente sofrendo todo dia. (José, 54 anos, diálise peritoneal).

Há de se pontuar que a diálise peritoneal ambulatorial contínua (DPAC) é menos invasiva e equivalente à hemodiálise. Ela mantém o adoecido sem sintomas indesejáveis, através da reposição parcial da função desempenhada pelos rins saudáveis, removendo substâncias em excesso no sangue, como ureia, creatinina, potássio, fosfato e água, para o dialisado infundido no peritônio (PECOITSFILHO; MORAES, 2014).

Entretanto, é imperativo destacar que, apesar de todo avanço tecnológico alcançado, ainda existem complicações associadas à DPAC, como a infecção do cateter abdominal, uma das principais causas de saída dessa modalidade de terapia (JACOBOWSKI; BORELLA; LAUTERT, 2005). Se tal situação depende da correta higienização do cateter e do ambiente onde estão inseridas as pessoas que a utilizam, fica claro que os problemas são extrínsecos ao procedimento em si.

O relato de José revela os benefícios da DPAC em sua vida, por possibilitar permanecer no ambiente familiar, evitando o desgaste de idas frequentes à clínica. Todavia, ao consultarmos o cadastro institucional no serviço de nefrologia referido questionamo-nos: por que existem 108 pessoas inscritas na modalidade de hemodiálise e somente nove em DPAC? As pessoas teriam medo? Estão esclarecidas sobre os benefícios de realizar a DPAC no próprio domicílio? As precárias condições clínicas e de vida dos adoecidos levam os profissionais de saúde a não indicar tal modalidade? É facultado aos adoecidos escolher? E por último, tal situação beneficia a quem? Certamente, a complexidade da questão merece estudo específico. 


\section{Considerações finais}

A experiência de adoecimento de pessoas com insuficiência renal crônica comporta impactos que integram de forma indissociada a dimensão material, concreta, e a dimensão imaterial, simbólica, dos significados, sentimentos, saberes e crenças. Nesse sentido, na experiência, fica clara a recusa à fragmentação e à cisão natureza-cultura.

Os impactos mais proeminentes nesta investigação abarcam o processo de tornar-se doente renal, com a notícia do diagnóstico, a indicação do tratamento contínuo, e também as repercussões do ser doente renal, advindas das intervenções biomédicas contínuas, além do próprio curso da enfermidade aliada ao desgaste corporal.

$\mathrm{Na}$ convivência com o tratamento e conforme o tempo de permanência nos serviços de saúde, o conhecimento do corpo, da diálise e das especificidades dos sinais e sintomas vão sendo reinterpretados continuamente, em decorrência da aprendizagem envolvida e aprimorada para lidar com as situações peculiares do cotidiano.

Entre os impactos do tratamento, destaca-se a relação com a máquina, que se mostrou ambígua, mobilizando sentimentos de gratidão por salvar suas vidas e, simultaneamente, de revolta, pela dependência e artificialidade do procedimento.

Os achados demonstram a complexidade de lidar com o adoecimento renal e o tratamento de diálise no cotidiano, revelando que os impactos são complexos e englobam as dimensões física e simbólica, que podem ser amplificados pelos aspectos sociais, culturais e econômicos contextuais que fragilizam e são indissociáveis na experiência. Destacam-se peculiaridades das pessoas entrevistadas, entre as quais, por estarem na faixa-etária produtiva, os impactos relacionados à impossibilidade de trabalhar foram recorrentes e mais acentuados entre os homens, relevando variações de gênero.

$\mathrm{O}$ estudo revela que, apesar do mesmo diagnóstico, os impactos diferem conforme as características dos adoecidos, suas histórias e contextos, o que implica necessidades de atenção não homogeneizantes, mas sensíveis às singularidades do adoecer. Assim, admitem-se as inúmeras influências nos impactos. No entanto, é imperativo recusar determinismos de distintas naturezas, como de classe e gênero, que devem sempre ser consideradas em suas intersecções, postas biograficamente e nunca definitivamente, de forma acabada. 
A abordagem da experiência de adoecimento privilegia e valoriza a perspectiva daquele que sofre com a condição, indissociável do contexto sociocultural. Porém, nunca se tem acesso à experiência em si, mas à sua representação e significação, já que o sujeito precisa colocar em suspensão o fluxo da vida cotidiana para refletir sobre suas vivências, imbuindo-as de sentido: a partir dessa interpretação é que se transforma em experiência. ${ }^{3}$

\section{Agradecimentos}

À Coordenação de Pessoal de Nível Superior (CAPES), nosso agradecimento pelo financiamento da pesquisa e concessão de bolsa de mestrado.

\section{Referências}

ALVES, P.C. A fenomenologia e as abordagens sistêmicas nos estudos sócio-antropológicos da doença: breve revisão crítica. Cad. Saúde Pública, Rio de Janeiro, v. 22, n. 8, p. 1547-1554, 2006. ALVES, P.C.B.; RABELO, M.C.M. Significação e metáforas na experiência da enfermidade. In: ALVES P.C.B.; RABELO, M.C.M.; SOUZA, I.M.A (Org.). Experiência da doença e narrativa. Rio de Janeiro: Fiocruz, 1999, p. 171-186.

AYRES, J.R.C.M. Cuidado e reconstrução das práticas de saúde. In: MINAYO, M.C.S.; COIMBRA J.R. (Org.). Críticas e atuantes: ciências sociais e humanas em saúde na América Latina. Rio de Janeiro: Editora Fiocruz, 2005. 708 p.

BARSAGLINI, R. A. Adoecimentos crônicos, condiçōes crônicas, sofrimentos e fragilidades sociais: algumas reflexôes. In: CANESQUI, A.M. (Org.). Adoecimentos e sofrimentos de longa duração. 2a ed. São Paulo: Hucitec, 2015, p. 78-101.

CANESQUI, A.M. Mudanças e permanências da prática alimentar cotidiana de famílias de trabalhadores. In: . (Org). Antropologia e nutrição: um diálogo possível. Rio de Janeiro: Fiocruz, 2005. p. 167-210. (Coleção Antropologia e Saúde).

. Estudos antropológicos sobre os adoecidos crônicos. In: . (Org.). Olhares socioantropológicos sobre os adoecidos crônicos. São Paulo: Hucitec; 2007. p. 19-51.

CORBIN, J.; STRAUSS, A. Managing chronic illness at home: three lines of work. Qualitative Sociology, v. 8, n. 3, p. 224-247, 1985.

CSORDAS, T. Embodiment as a paradigm for anthropology. Ethos, v. 18, n. 1, p. 5-47, 1990. . Embodiment and experience. Cambridge: Cambridge University Press, 1994.

DENZIN, N. K. Interpretive Biography. Newbury Park: Sage Publications, 1989.

DUARTE, L. F. Da vida nervosa nas classes trabalhadoras urbanas. Rio de Janeiro: Zahar; 1986. 290p. 

. Indivíduo e pessoa na experiência da saúde e da doença. Ciência \& Saúde Coletiva, Rio de Janeiro, v. 8, n. 1, p. 173-183, 2003.

FERREIRA, J. O corpo sígnico. In: ALVES, P.C. (Org.) Saúde e doença: um olhar antropológico. Rio de Janeiro: Fiocruz, 1994.

FONTANELLA, B.J.B.; RICAS, J.; TURATO, E.R. Amostragem por saturação em pesquisas qualitativas em saúde: contribuiçōes teóricas. Cad. Saúde Pública. Rio de Janeiro, v. 24, n. 1, p. 17-27, jan. 2008.

FRANK, A.W. The wounded storyteller: body, illness, and ethics. $2^{\text {a }}$ ed. Chicago: University of Chicago Press; 2013.

GOFFMAN, E. Estigma: notas sobre a manipulação da identidade deteriorada. 4. ed. Rio de Janeiro: LTC Editora, 1988.

GOMES, R. Sexualidade e Masculinidade: a trama das palavras. In: Sexualidade masculina, gênero e saúde. Rio de Janeiro: Fiocruz, 2008. p. 59-97.

GONÇALVES, C.S. As representaçôes sociais sobre a doença renal crônica. 2012. $82 \mathrm{f}$. Dissertação (Mestrado em Enfermagem) - Setor de Ciências da Saúde, Universidade Federal do Paraná, Curitiba, 2012.

HARAWAY, D. Antropologia do ciborgue: as vertigens do pós-humano. TADEU, T. (Org.) 2. ed. Belo Horizonte: Autêntica; 2009.

ILLICH, I. A expropriação da saúde: nêmesis da medicina. Rio de Janeiro: Nova Fronteira, 1975.

JACOBOWSKI, J.A.D.; BORELLA, R.; LAUTERT, L. Pacientes com insuficiência renal crônica: causas de saída do programa de diálise peritoneal. Revista Gaúcha de Enfermagem, v. 26, n. 3, p. 381-391, 2005.

LE BRETON, D. Antropologia del cuerpo y modernidad. Buenos Aires: Edit. Nueva Visión; 1995. 254p.

Sociologia do corpo. Petrópolis: Vozes, 2007. . Antropologia do corpo e modernidade. Trad. F. S. C. Lopes. Rio de Janeiro: Vozes, 2011.

LUBKIN, I.M.; LARSEN, P. What is chronicity? In: . (Org.) Chronic illness: impact and interventions. 5. ed. Sudbury: Jones \& Barlett Lerning, 2002. p. 3-24.

LUGON, J.R.; MATTOS, J.P.S.; WARRAK, E.A. Hemodiálise. In: RIELLA, M.C. (Org.). Princípios de nefrologia e distúrbios hidroeletrolíticos. 5. ed. Rio de Janeiro: Guanabara Koogan, 2014. p. 681-1031.

LUZ, E. L.; BASTO, M. L. Vozes das pessoas com DPOC: o processo de tornar-se doente crónico. Ciência \& Saúde Coletiva, v. 18, n. 8, p. 2221-2228, 2013. 
MARTINS, C.; RIELLA M. Terapia nutricional do paciente renal crônico e agudo. In:

RIELLA, M.C. Princípios de nefrologia e distúrbios hidroeletrolíticos. 5. ed. Rio de Janeiro: Guanabara Koogan, 2014, p. 939-959.

MATTOS, M.; MARUYAMA, S.A.T. A experiência em família de uma pessoa com diabetes mellitus e em tratamento por hemodiálise. Rev. Eletr Enf., v. 11, n. 4, p. 971-981, 2009.

MELEIS, A.L.; TRANGENSTEIN, P.A. Facilitating transitions: redefinition of the nursing mission. Nurs Outlook, v. 42, p. 255-259, 1994.

MERCADO-MARTINEZ, F. J. et al. Vivendo com insuficiência renal: obstáculos na terapia da hemodiálise na perspectiva das pessoas doentes e suas famílias. Physis: Revista de Saúde Coletiva. Rio de Janeiro, v. 25, n. 1, p. 59-74, 2015.

MINAYO, M.C.S. (Org). Pesquisa social: teoria, método e criatividade. 30. ed. Petrópolis: Vozes; 2011.

NARDI, H.C. O ethos masculino e o adoecimento relacionado ao trabalho. In: DUARTE L.F.D (Org.). Doença, sofrimento, perturbação: perspectivas etnográficas. Rio de Janeiro: Fiocruz, 1998.

PECOITS-FILHO, R.; MORAES, T.P. Diálise peritoneal. In: RIELLA, M.C. (Org.) Principios de nefrologia e distúrbios hidroeletroliticos. 5. ed. Rio de Janeiro: Guanabara Koogan; 2014, p. 1032-46.

RAYNAUT, C. Interfaces entre a antropologia e a saúde: em busca de novas abordagens conceituais. Rev Gaúcha Enferm., v.27, n.2, p. 149-65, 2006.

RAMOS, I.C. et al. Portador de insuficiência renal crônica em hemodiálise: significados da experiência vivida na implementação do cuidado. Acta Sci Health Sci., v. 30, n. 1, p. 73-79, 2008.

RODRIGUES, D.F. et al. Vivências dos homens submetidos à hemodiálise acerca de sua sexualidade. Avances en enfermeria, v. 29, n. 2, p. 255-262, 2011.

SCHUTZ, A. Bases da fenomenologia. In: WAGNER, H. (Org.). Fenomenologia e relaçôes sociais: textos escolhidos de Alfred Schutz. Rio de Janeiro: Zahar, 1979.

SEPARAVICH, M.A. Saúde masculina: representação e experiência de homens trabalhadores com o corpo, saúde e doença. 2014. 188 f. Tese (Doutorado em Saúde Coletiva) - Faculdade de Ciências Médicas, Universidade Estadual de Campinas, Campinas, 2014.

SEPARAVICH, M.A.; CANESQUI, A.M. Girando a lente socioantropológica sobre o Corpo: uma breve reflexão. Saúde Soc. São Paulo, v. 19, n. 2, p. 249-259, 2010.

STRAUSS, A. Work and the division of labor. Sociological Quarterly, v. 26, n. 1, p. 1-19, 1985.

TERRA, F.S. et al. O portador de insuficiência renal e sua dependência ao tratamento hemodialítico: compreensão fenomenológica. Rev. Bras. Clin. Med. v. 8, n. 4, p. 306-310, 2010. 
VÍCTORA, C. G. Pesquisa qualitativa em saúde: uma introdução ao tema. Porto Alegre: Tomo Editorial, 2000. 136p.

ZATZ, R. Patogênese e fisiopatologia da doença renal crônica (DRC). In: RIELLA, M. C. (Org.) Princípios de nefrologia e distúrbios hidroeletrolíticos. 5. ed. Rio de Janeiro: Guanabara Koogan, 2014, p. 804-814.

ZILLMER, J.G.V.; SILVA, D.G.V.; MERCADO-MARTINEZ, F.J. Sobre o meu corpo mando eu! O manejo do tratamento na vida das pessoas em diálise peritoneal. Atas, v. 1, p. 303-309, 2015.

\section{Notas}

${ }^{1}$ A expressão "pegava muito peso" é comum no vocabulário dos adoecidos renais, referindo à quantidade de líquido a ser "dialisado"/"retirado" durante a hemodiálise. Quando se ingerem mais líquidos, o peso do paciente aumenta e, consequentemente, aumenta o "peso" a ser retirado na sessão. Esse conhecimento quanto à quantidade de peso a ser retirado nas sessôes é algo aprimorado com o tempo e integra a experiência de todos os participantes.

${ }^{2}$ Diante da necessidade de deslocamento do local de tratamento, o adoecido e o serviço de saúde especializado precisam verificar a possibilidade de vaga para realizar diálise no local de destino, uma vez que a não realização do tratamento (semanalmente) gera consequências e mal-estar ao adoecido. No entanto, esse remanejamento de vagas é algo complicado, burocratizado e nem sempre viável de ser realizado.

${ }^{3}$ P. L. de Lemos desenvolveu a pesquisa original, coleta, análise e interpretação dos dados, elaboração do artigo e revisão crítica do conteúdo intelectual, revisão final do texto a ser publicado. R. Barsaglini orientou a pesquisa original; participou da análise e interpretação dos dados, elaboração do artigo e revisão crítica do conteúdo intelectual, revisão final do texto a ser publicado. K. M. R. da Paz participou da análise e interpretação dos dados e da elaboração do artigo. 
Tangible and intangible impacts on the experience of chronic kidney illness

A socio-anthropological study of qualitative approach that analyzed the tangible and intangible impacts on the illness experience of adult patients with chronic renal failure (CRF) and on dialysis treatment. Data were analyzed in the light of thematic analysis and obtained through interviews guided by a semi-structured script together with the technique of drawings elaborated by participants. The results were organized in two topics, showing the impacts resulting from the process of developing kidney disease. This process comprises the repercussions of the discovery, the formal diagnosis and indication of dialysis, the impact of having kidney disease from the continuous treatment and its repercussions (dialysis, the body-machine interface), the progression of the disease and its consequences. The impacts involve tangible and intangible aspects, including weakness and constant pain, a relationship of anger and gratitude with the dialysis machine, marks caused by arteriovenous fistula, comorbidities, depression, iatrogenic, social isolation, among others. The conclusion is that different impacts generated by CRF do not dissociate from its bodily existence and are amplified or mitigated by biographical, social, cultural and economic aspects. Moreover, despite sharing the same diagnosis, each person experiences CRF and its impacts in a singular way.

Key words: chronic renal failure; impacts; experience of illness. 